\title{
SISTEMA PREVIDENCIÁRIO SOB A ÓTICA DAS FINANÇAS COMPORTAMENTAIS
}

\author{
SOCIAL SECURITY SYSTEM IN THE \\ PERSPECTIVE OF BEHAVIORAL FINANCE
}

Recebido 21/09/2010

Aceito $01 / 12 / 2011$

Marcelo Nascimento ${ }^{1}$ Vanessa Marcela Nascimento ${ }^{2}$ Juliane Vieira de Souza ${ }^{3}$ Hans Michael Van Bellen ${ }^{4}$

\section{RESUMO}

A decisão de como e onde investir o dinheiro está ligada ao nível de risco que se deseja assumir em relação ao retorno esperado. Assim, este artigo buscou demonstrar a influência do comportamento humano quanto ao crescimento dos fundos de investimentos no Brasil, por meio de um levantamento de dados pertinentes à previdência. A presente pesquisa é exploratória, prática, com fonte de dados primária e secundária. O estudo é qualitativo-quantitativo e de natureza indutiva. Os resultados demonstraram que: a maioria das pessoas ou não faz planejamento em longo prazo (63\%) ou o faz para, no máximo, os próximos cinco anos (40\%); 37\% esperam ganhar de 9 a 12 salários; 40,0\% dos respondentes investem em planos de previdência ou pretendem fazer outros investimentos (43\%); $77 \%$ dos respondentes investiriam num plano de previdência e $80,0 \%$ manifestaram a crença de que haveria o recebimento da aposentadoria; $67,0 \%$ dos respondentes não contribuiriam com o INSS caso este fosse facultativo; em relação às denúncias de fraude no INSS, 73\% acham que estas vão interferir em sua aposentadoria futura. Como conclusão, observa-se que, embora as pessoas acreditem que não receberiam seu benefício futuramente, a maioria tem mais segurança no INSS do que nos planos de previdência privada.

Palavras-chave: Comportamento Humano; Aposentadoria; Finanças Comportamentais; INSS; Previdência.

\footnotetext{
${ }^{1}$ Mestrando em Administração, formado em Ciências Contábeis pela Universidade Federal de Santa Catarina (UFSC), Florianópolis, Santa Catarina, Brasil. E-mail:mn_marcelo@yahoo.com.br

${ }^{2}$ Mestranda em Contabilidade na Universidade Federal de Santa Catarina e Contadora pela Universidade Federal de Santa Catarina, Florianópolis, Santa Catarina, Brasil. Atualmente é contadora da Secretária da Fazenda do Estado de Santa Catarina. E-mail: vanessanasci@ yahoo.com.br

${ }^{3}$ Mestrado em Contabilidade na Universidade Federal de Santa Catarina e Especialista em Auditoria empresarial pela Universidade do Sul de Santa Catarina, Santa Catarina, Brasil. Atualmente está Lotada na Fundação Educacional de São José no Cargo de Contadora Publica. E-mail: juliane@radioguararema.com.br

${ }^{4}$ Doutorado em Engenharia de Produção pela Universidade Federal de Santa Catarina (2002), Atualmente é professor adjunto da Universidade Federal de Santa Catarina, Florianópolis, Santa Catarina, Florianópolis, Brasil. Atua como docente e pesquisador nos programas de pós-graduação em Administração e Contabilidade. E-mail: hansmichael@cse.ufsc.br
} 


\section{ABSTRACT}

The decision of as and where to invest the money he is on to the risk level that if it desires to assume in relation to the waited return. Thus, this article searched to demonstrate the influence of the human behavior in relation to the growth of the investment funds in Brazil by means of a pertinent data-collecting to the providence. The present research is exploratory, practical, with primary and secondary source of data. The study he is qualitative-quantitative, and has an inductive nature. The results had demonstrated that: the majority of the people or does not make planning in long stated period (63\%), or it makes it stops in the maximum next the five years (40\%); 37\% wait to earn of 9 the 12 wages; $40.0 \%$ of the respondents invest in providence plans, or intend to make other investments (43\%); $77 \%$ of the respondents would invest in a providence plan and $80.0 \%$ had revealed belief of that it would have the act of receiving of the retirement; $67.0 \%$ of the respondents would not contribute with the INSS case this were facultative; in relation to the denunciations of fraud in INSS, 73\% they find that they go to intervene with its future retirement. As conclusion it is observed that even so the people believe that they would not receive its benefit future, the majority have more security in the INSS of what plain of private providence.

Keywords: Human Behavior; Retirement; Behavioral Finance; INNS; Foresight.

\section{INTRODUÇÃO}

A decisão de como e onde investir o dinheiro está ligada ao nível de risco que se deseja assumir em relação ao retorno esperado. Para Menezes (2007), o investimento é a aplicação de recursos correntes na esperança de obter recursos adicionais no futuro, de modo que compense o risco corrido e também o consumo que adiado. A expectativa futura de ter estabilidade de vida depois de determinada idade estimula as pessoas a investirem parte de sua renda num fundo de investimento, para garantir a tão esperada aposentadoria.

Segundo Begg (1982), essa seria a expectativa matemática sobre o valor futuro de determinadas variáveis, dadas a estimação de risco e as informações disponíveis na data em que as expectativas são geradas. Considerando alguns fatores externos, tais como mudanças de governo e alterações de mercado, que podem interferir nos fundos de investimento, não existe a possibilidade de saber antecipadamente cada uma das hipóteses que compõem o valor futuro de cada uma dessas variáveis, e o investidor, nesse caso, trabalha com o conceito de probabilidade subjetiva.

Se as expectativas são geradas de forma subjetiva e sob condições de incerteza, então, as mesmas poderiam estar sujeitas a certas tendências observadas por Kahneman e Tversky em seu artigo intitulado "Judgment under Uncertainty: Heuristics and Biases" (1974). Então, se as expectativas forem assim influenciadas, e estas, por sua vez, serão representadas por expectativas matemáticas, conforme defende Begg (1982), então tanto os impactos da condição de incerteza, quanto a operação do fundo de investimento deveriam influenciar no crescimento dos mesmos.

Este trabalho propõe uma reflexão sobre a influência do comportamento humano em relação ao crescimento dos fundos de investimentos, sob a ótica das finanças comportamentais. Dessa forma, visa-se a evidenciar como as condições de incertezas e as expectativas subjetivas a respeito da previdência podem influenciar no crescimento desse setor.

Primeiramente, serão definidos os benefícios concedidos pelo INSS e pelos fundos de investimentos fechados e abertos. Posteriormente, serão destacados suas variáveis críticas e seus riscos. Observadas essas variáveis subjetivas, será elaborada uma análise dos dados previdenciários dos fundos de investimentos público e privado e do INSS. Em seguida, será aplicado um questionário aos acadêmicos do curso de Ciências Contábeis para verificar suas expectativas futuras em relação a sua aposentadoria. O universo de pesquisa é a amostra de uma população total de formandos com idade média de 26 anos. Esta foi escolhida estrategicamente, pois os estudantes pesquisados 
possuem tempo de vida para planejar, cuidadosamente, sua aposentadoria, já que, no Brasil, o tempo de contribuição ao INSS é de 35 anos para homens e de 30 anos para mulheres.

Congregar o comportamento humano aos modelos financeiros econômicos proporcionará maior percepção do mundo real. A presente pesquisa procura aplicar finanças comportamentais para estudar se as expectativas dos futuros aposentados ou pensionistas influenciam, de alguma forma, o mercado de fundos de investimentos.

\section{SISTEMA OFICIAL DA PREVIDÊNCIA SOCIAL}

Wladimir Martinez (1997) aponta que "o fato de as pessoas estarem vivendo mais é o dado demográfico e sociológico mais importante do final do século XX". Os problemas relacionados à previdência social no Brasil têm uma persistência histórica. Nos últimos anos, o governo brasileiro tem apontado para um novo elemento que aprofunda a atual situação deficitária do sistema: o envelhecimento da população, um dos motivos levantados para a reforma previdenciária na década de 90.

O sistema oficial de previdência no Brasil não tem sido capaz de garantir aos trabalhadores a proteção da sua qualidade de vida durante a aposentadoria, resultando em que estes, inexoravelmente, sejam expulsos do mercado consumidor no momento em que encerram o período laborativo. Em todo o mundo desenvolvido, especialmente nos Estados Unidos, na Alemanha e no Japão, o sistema complementar privado é que resolveu essa questão (ABRAPP 2007).

\subsection{Benefícios concedidos pelo INSS e pelos fundos de investimentos}

A Previdência Social é uma instituição pública que tem como objetivo reconhecere conceder direitos aos seus segurados e que tem como função garantir que as fontes de renda do trabalhador e de sua família sejam mantidas quando ele perde a capacidade de trabalhar temporariamente (doença, acidente, maternidade) ou permanentemente (morte, invalidez e velhice).

A Previdência Social possui 10 tipos de benefícios entre eles:

\begin{tabular}{|l|l|}
\hline Aposentadoria por idade & Auxílio-reclusão \\
\hline Aposentadoria por invalidez & Pensão por morte \\
\hline Aposentadoria por tempo de contribuição & Salário-maternidade \\
\hline Aposentadoria especial & Salário-família \\
\hline Auxilio-Doença para empresa convenente & $\begin{array}{l}\text { Benefício assistencial ao idoso e ao } \\
\text { deficiente (benefício assistencial) }\end{array}$ \\
\hline Auxílio-doença & $\begin{array}{l}\text { Reabilitação profissional } \\
\text { (serviço previdenciário) }\end{array}$ \\
\hline Auxílio-acidente & Serviço Social (serviço previdenciário) \\
\hline
\end{tabular}

Quadro 1 - Tipos de Benefícios. Fonte: Adaptado de Inss (2007)

Em relação aos Fundos de Investimentos, a ANBID (2007), Associação Nacional dos Bancos de Investimento, assim os define: "é um condomínio que reúne recursos de um conjunto de investidores, com o objetivo de obter ganhos financeiros a partir da aquisição de uma carteira 
de títulos ou valores mobiliários". Para regulamentar a utilização dos fundos de investimentos, foi criada a lei complementar n. 109, que organiza a previdência privada em dois níveis: o das entidades fechadas, específicas dos empregados de determinada empresa ou grupo de empresas; e o das entidades abertas, acessíveis a qualquer um que subscreva e custeie o seu plano de benefícios.

$\mathrm{O}$ regime das entidades fechadas, ou Fundos de Pensão, diferencia-se do outro regime por diversos aspectos fundamentais, entre estes, o fato de não visarem à distribuição de lucros e de preverem contribuições de duas fontes, do trabalhador participante e de sua empresa empregadora. Os fundos de pensão seriam então definidos como:

\begin{abstract}
"Espécie de pecúlio ou poupança formada por um conjunto de pequenos investidores e poupadores, com o intuito de garantir para si uma pensão mensal, depois de um prazo determinado. Em geral, os fundos de pensão (assim como pecúlios e outros sistemas da previdência privada) são organizados por empresas financeiras que fazem aplicações com a soma dos dinheiros dos pequenos poupadores". (BANCO DE POUPANÇA E CRÉDITO, 2007)
\end{abstract}

Esta aplicação dos dinheiros dos pequenos poupadores é o que lhes dá grande vitalidade e eficiência comparativamente ao regime da Previdência Social, que é o da repartição simples, ou o orçamentário. Assim, o trabalhador participante forma totalmente os recursos garantidores dos seus benefícios durante o período laborativo, de tal forma que, ao se aposentar, toda a massa de recursos estará estocada. Seria esse então, o ponto crucial a ser resguardado pelos fundos de investimentos: assegurar que todos os recursos estejam estocados. Seus benefícios são: Pensão ao Cônjuge/Companheiro, Pensão aos Filhos Menores, Pensão por Prazo Certo e Pecúlio.

\title{
2.2 Variáveis críticas e seus riscos
}

Existem algumas variáveis e alguns riscos que devem ser demonstrados quando da análise, seja do benefício do INSS, ou seja, dos planos de previdência. Pode-se, assim, citar o Escândalo dos fundos de pensão, que veio a tona durante a crise do Mensalão, no governo brasileiro do presidente Luiz Inácio Lula da Silva (PT/ 2002-2006). Foram feitas denúncias de que algumas instituições financeiras estariam a receber investimentos de entidades privadas de previdência complementar através de um esquema montado pelo empresário Marcos Valério.

Segundo o Jornal do Senado (2006) as investigações da Sub-relatoria dos fundos de pensão basearam-se no cruzamento de dados e na avaliação dos mercados, na análise dos processos de gestão dos fundos de pensão, na investigação dos indícios de esquemas e grupos organizados.

Constatou-se que nos fundos de pensão investigados, problemas decorrentes do aparelhamento partidário, no qual profissionais desqualificados, sem o preparo adequado para ocupar cargos relevantes nas entidades, eram nomeados. Isso acabou permitindo que houvesse investimentos de alto risco, mais especificamente, em aplicações em bancos de segunda linha, sem aparente justificativa, e registro de rentabilidades negativas ou e queda do valor dos recursos garantidores das reservas técnicas, devido ao mau gerenciamento dos investimentos.

Ao mesmo tempo em que os fundos perdiam somas vultosas nas negociações financeiras, corretoras auferiam lucros exorbitantes, muito acima dos valores de mercado. As perdas começaram a aumentar exponencialmente, ano a ano, a partir de 2002, indo até 2005 , ano em que as perdas sofreram uma queda brusca, coincidindo com as denúncias divulgadas pela imprensa a respeito do então deputado Roberto Jefferson, sobre o mensalão.

Mais de $\mathrm{R} \$ 100$ milhões da poupança para a aposentadoria de 75 mil funcionários públicos foram parar nas mãos dos operadores do mensalão. Os fundos, que são os investidores mais ricos 
do país, teriam perdido dinheiro - fraudando os associados de propósito. Na outra ponta, a dos que embolsavam o produto da fraude, aparece um grupo de operadores de São Paulo.

Assim, o esquema funcionava na BM\&F, onde há duas opções: de um lado, os investidores acreditam na alta da bolsa e compram contratos futuros de índice; do outro, os que apostam na baixa e vendem contratos. Na data final da operação, por exemplo, se a bolsa subiu, ganha quem comprou. Foi nesse mercado que operações foram simuladas - ou seja, a BM\&F e a CVM suspeitam que os fundos optaram de propósito pelo lado perdedor.

Portanto, o prejuízo ficava sempre com as fundações e o lucro com os especuladores do mensalão e as empresas em paraísos fiscais (offshore). Essa estratégia tinha dois objetivos: tirar dinheiro dos fundos de pensão e levar os recursos para fora do país. A simulação da aposta no mercado financeiro servia para justificar a saída do dinheiro dos fundos. (REVISTA ÉPOCA, 2007). Assim, os fundos citados seriam:

\begin{tabular}{|l|l|}
\hline Centros (Banco Central) & Postalis (Correios) \\
\hline Eletros (Eletrobrás) & Prece \\
\hline Funcef (Caixa Econômica) & Previ (Banco do Brasil) \\
\hline Geap (servidores públicos federais) & Real Grandeza (Furnas) \\
\hline Nucleos (Eletronuclear) & Refer (ferroviários) \\
\hline Petros (Petrobras) & Serpros (Serpro) \\
\hline Portus (da extinta Portobrás) & \\
\hline
\end{tabular}

Quadro 2- Fundos Citados. Fonte: Adaptado Jornal do Brasil - 22/02/2006

Em relação às corretoras, que são empresas que fazem negócios com o mercado financeiro por meio da compra e venda de ações, de títulos públicos e privados e de produtos mais sofisticados, como contratos em moedas estrangeiras, pode-se citar a Bonus-Banval e a Laeta.

Já em relação ao Instituto Nacional da Seguridade Social (INSS), os riscos envolvidos seriam, segundo o IBGE (2004), o envelhecimento da população, o aumento da expectativa de vida e o controle de natalidade, que diminui a arrecadação e aumenta as despesas do Inss, sendo que esse sistema de aposentadoria pode entrar em colapso até 2050. A projeção do IBGE revela, ainda, um dado interessante: a população com mais de 80 anos crescerá $8,8 \%$ ao ano, por duas décadas, saindo dos atuais 2,3 milhões para 13,7 milhões em 2050, agravando ainda mais a situação da previdência no país.

Outras variáveis seriam denúncias de incorreções e de mau uso do sistema previdenciário no Brasil. Essas fraudes lesam os cofres do INSS em milhares de reais. Inúmeros casos já vieram à tona, mas o que chama mais a atenção é o débito das empresas e do governo com o INSS. Conforme o demonstrado pelo próprio Instituto Nacional de Seguridade Social essa divida é de aproximadamente 83 bilhões de reais, isso por si só é maior que qualquer irregularidade que possa ter o sistema. Assim, já que este é deficitário, cabe ao Governo, através de seu orçamento, retirar esses valores para cobrir os benefícios, gerando carências em outras áreas e provocando um ciclo vicioso e prejudicial ao país. 
2.3 Análise dos dados previdenciários dos fundos de investimentos e do INSS

A boa gestão dos ativos de investimento proporcionou, no ano de 2006, um ótimo retorno para as entidades. A rentabilidade média estimada das carteiras no ano foi de $23,6 \%$. Esse resultado é sensivelmente maior que a meta atuarial medida pelo INPC $+6 \%$, que terminou o ano acumulada em $8,98 \%$. Na Renda Fixa, o retorno estimado foi de $16,1 \%$ e, na Renda Variável, $41,4 \%$. Conforme a ABRAPP, sua rentabilidade vem tendo a seguinte variação, seguida pela evolução de seus ativos:

\begin{tabular}{|l|c|c|c|c|}
\hline \multicolumn{3}{|c|}{ CRESCIMENTO DO INVESTIMENTOS } & \multicolumn{2}{c|}{ R\$ MILHOES) } \\
\hline \multirow{2}{*}{ PERÍODO } & \multicolumn{2}{|c|}{ INVESTIMENTOS } & \multirow{2}{*}{ VARIAÇÃO } & VARIAČ̃̃ \\
\cline { 2 - 3 } & INICIAL & FINAL & MÉDIA ACUM. \\
\hline 1996 & 57.461 & 71.672 & $24,70 \%$ & $24,17 \%$ \\
\hline 1997 & 71.672 & 86.861 & $21,20 \%$ & $23,17 \%$ \\
\hline 1998 & 86.861 & 90.757 & $4,50 \%$ & $18,20 \%$ \\
\hline 1999 & 90.757 & 115.125 & $26,80 \%$ & $19,89 \%$ \\
\hline 2000 & 115.124 & 130.077 & $13,00 \%$ & $18,71 \%$ \\
\hline 2001 & 130.007 & 154.578 & $18,80 \%$ & $18,73 \%$ \\
\hline 2002 & 154.578 & 168.498 & $9,00 \%$ & $17,46 \%$ \\
\hline 2003 & 168.498 & 216.180 & $28,30 \%$ & $18,62 \%$ \\
\hline 2004 & 216.180 & 255.788 & $18,30 \%$ & $18,59 \%$ \\
\hline 2005 & 255.788 & 295.250 & $15,40 \%$ & $18,30 \%$ \\
\hline 2006 & 295.250 & 352.196 & $19,30 \%$ & $18,38 \%$ \\
\hline
\end{tabular}

Quadro 3 - Evolução e Rentabilidade de Ativos. Fonte: Consolidado Estatístico 2006 ABRAPP.

\section{EVOLUÇÃO DOS ATIVOS}

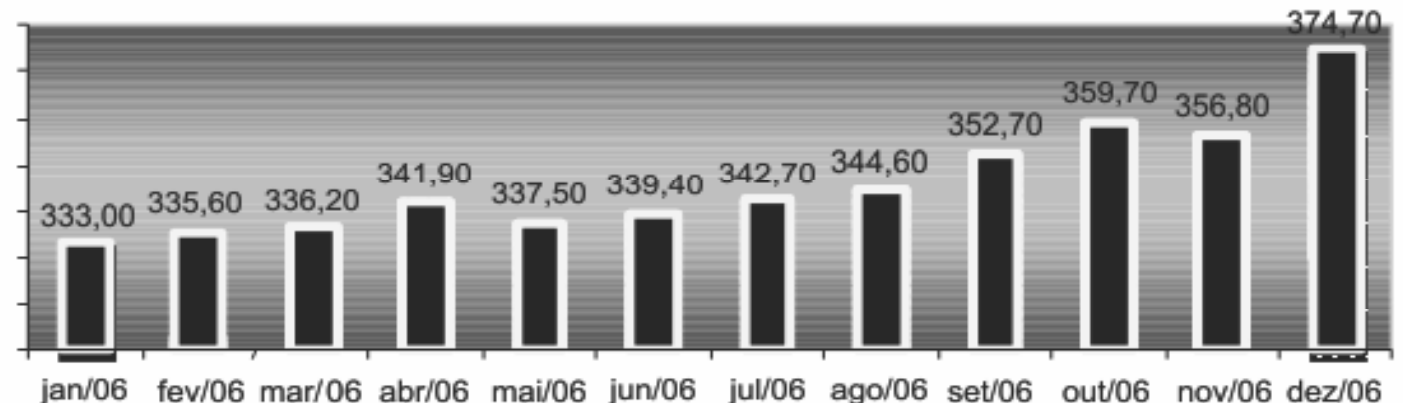

Figura 1 - Evolução e Rentabilidade de Ativos. Fonte: Consolidado Estatístico 2006 ABRAPP

Nesse sentido, o crescimento dos fundos de previdência se deu por diversos fatores, além da necessidade de complementar os níveis salariais do período laboral. 0 crescimento da média etária proporciona grande massa de participantes aos fundos da previdência, aumentando seus patrimônios. Também é importante o fato de as contribuições serem integralmente dedutíveis do Imposto de Renda da Pessoa Física (IRPF). Pode-se demonstrar o aumento dos ativos da seguinte maneira: 


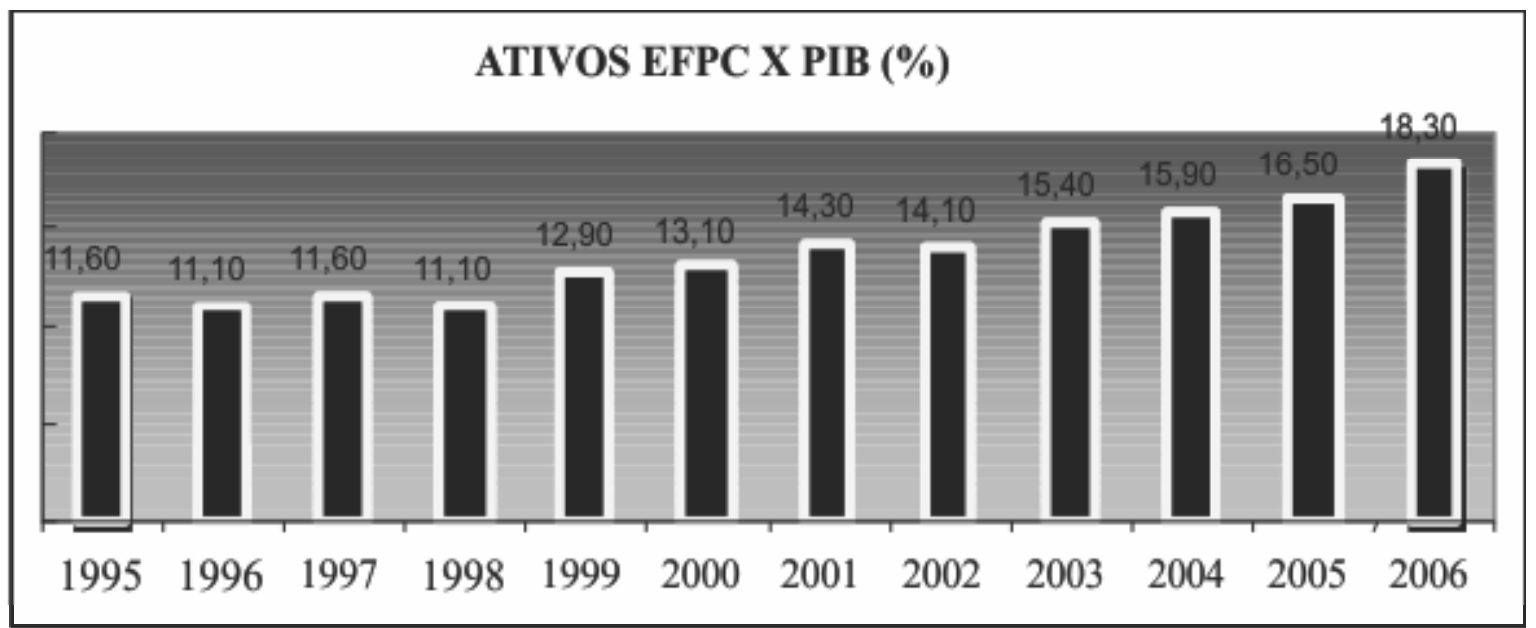

Figura 2 - Evolução e Rentabilidade de Ativos. Fonte: Consolidado Estatístico 2006 ABRAPP

Isso também se deve ao fato de as pessoas estarem procurando complementar sua aposentadoria da previdência social adquirindo, antecipadamente, um plano de previdência complementar, devido ao valor do benefício máximo da previdência, que é de $R \$ 2.801,56$. A renda mensal paga pelos fundos de pensão segundo a ABRAPP é a seguinte:

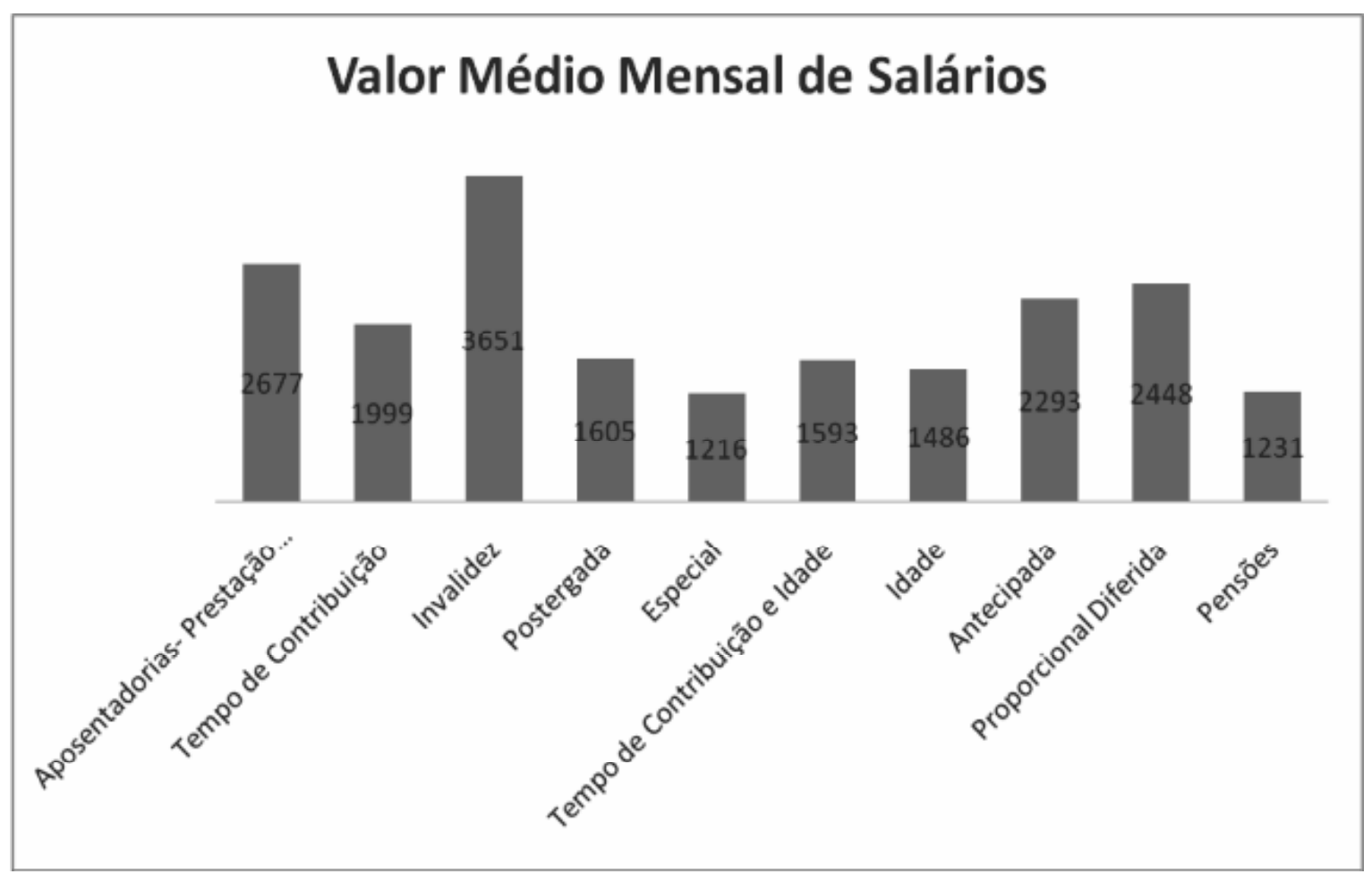

Figura 3 - Evolução e Rentabilidade de Ativos. Fonte: Consolidado Estatístico 2006 ABRAPP

Com relação ao INSS, este paga, mensalmente, 21,5 milhões de benefícios que servem ao orçamento de aproximadamente 74 milhões de brasileiros ( $40 \%$ da população brasileira), considerados os impactos na renda familiar dos beneficiários. Esse Regime Geral de Previdência, que protege mais de 50 milhões de brasileiros e brasileiras, os quais são segurados/ contribuintes ou beneficiários, é crucial para a economia local de vários municípios. 
Dentre as cidades brasileiras com melhor IDH, a maioria recebe mais recursos da Previdência Social sob a forma de pagamento de benefícios do que repasses do Fundo de Participação dos Municípios (FPM). Já entre as cidades com pior IDH, uma minoria recebe mais em benefícios previdenciários e assistenciais (também pagos pelo INSS) do que do FPM. Pode-se dizer, assim, que existe forte correlação entre os pagamentos da Previdência Social e a melhoria da condição de vida da população brasileira. "Todos os meses, 18 milhões de brasileiros superam a linha da pobreza ao receberem um salário mínimo pago pela Previdência Social.". Assim o seu valor arrecadado e o valor do benefício são respectivamente:

\begin{tabular}{|c|c|c|c|c|}
\hline 2000 & 2001 & 2002 & 2003 & 2004 \\
\hline R\$ 57.156.734.454 & RS 65.423.797.0130 & R\$ 75.535.139.098 & R\$ 86.525.555.627 & R\$ 99.972.543.556 \\
\hline
\end{tabular}

\begin{tabular}{|c|c|}
\hline GRUPOS DE ESPECIES & TOTAL BRASIL \\
\hline TOTAL & $\mathrm{R} \$ \quad 10.407 .506 .504,87$ \\
\hline CLIENTELA URBARA & $R \$ \quad 8.529 .416 .027,32$ \\
\hline Aposentadoria por idade urbana & $790.063 .551,45$ \\
\hline Aposentadoria por invalidez urbana & $888.190 .212,86$ \\
\hline Aposentadoria por tempo de contribuição urbana & $3.330 .165 .829,42$ \\
\hline Pensão por morte urbana & $1.805 .744 .196,57$ \\
\hline Auxílio-doe nça urbano & $752.885 .325,99$ \\
\hline Auxílio-reclus̃o urbano & $5.384 .425,33$ \\
\hline Auxílio-acidente urbano & $2.068 .893,88$ \\
\hline Rendas mensais vitalícias por idade urbano & $23.269 .501,12$ \\
\hline Rendas mensais vitalícias por invalide $\mathrm{z}$ urbano & $57.000 .601,90$ \\
\hline Armparo social do idoso & $243.552 .740,51$ \\
\hline Arnparo social do deficiente & $295.152 .716,29$ \\
\hline Pensões mensais vitalícias urbanas & $9.237 .138,80$ \\
\hline Salário farnília & 1,15 \\
\hline Salário mate midade urbano & $8.691 .775,07$ \\
\hline Abono de serviço urbano - $20 \%$ & $940.212,36$ \\
\hline Abono de serviço urbano - $25 \%$ & $44.947,52$ \\
\hline Pecúlio & $2.718,35$ \\
\hline Auxílio-doe nça acide nte urbano & $91.584 .842,71$ \\
\hline Aposentadoria acidentária urbano & $76.443 .771,56$ \\
\hline Pensão acidentária urbana & $69.174 .897,63$ \\
\hline Auxílio-acidente acidentário urbano & $71.770 .834,54$ \\
\hline Auxílio-suplementar acidentário urbano & $8.046 .892,31$ \\
\hline CLIENTELARURAL & $R \$ \quad 1.878 .090477,55$ \\
\hline Aposentadoria por idade rural & $1.174 .701 .936,34$ \\
\hline Aposentadoria por invalidez rural & $114.065 .179,43$ \\
\hline
\end{tabular}

Quadro 5 - Valor De Benefícios Emitidos Por Unidades Da Federação, Segundo Os Grupos De Espécies - Posição Em Dezembro De 2004-(Em R\$). Fonte: MPS - DATAPREV, Síntese 2004 


\subsection{Influência dos fatores subjetivos no crescimento dos fundos de investimentos}

Neste tópico, será demonstrado o resultado da Pesquisa de Opinião feita em 13/06/2007. Foram entregues questionários a 30 pessoas, homens e mulheres, universitários da Universidade Federal de Santa Catarina, cuja faixa etária é de 25 nos.

Foram questionados vários assuntos a respeito do Plano de Previdência e do INSS. 0 principal objetivo da pesquisa foi realizar levantamento de dados pertinentes à previdência, seja ela publica ou privada, bem como relacioná-los a expectativa de renda que dos pesquisados ao se aposentarem.

Outros pontos foram levantados, como as denuncias de fraude e seu reflexo sobre a aposentadoria e crença sobre se receberiam ou não o benefício no futuro.

Assim, os resultados da pesquisa demonstraram que a maioria das pessoas ou não faz planejamento a longo prazo (63\%), ou o faz para, no máximo, os próximos cinco anos (40\%). Quanto ao o que as pessoas imaginam estar fazendo aos 65 anos, a maioria espera estar aposentada. Isso demonstra que, embora a maioria dos indivíduos adultos não planejem seu futuro a longo prazo, eles esperam estar aposentados aos 65 anos.

No quesito faixa de renda na aposentadoria, houve uma distribuição muito parecida em relação à expectativa de renda, no qual $30 \%$ esperam ganhar de quatro a oito salários, $37 \%$ esperam ganhar de 9 a 12 salários, e o restante (33\%) mais de doze salários.

Quando se tratou de garantir uma aposentadoria estável, a maioria dos entrevistados revelou que pretende ou investir em planos de previdência ( $40 \%$ ) ou fazer outros investimentos (43\%). Isso ratifica a resposta dada à questão seguinte, na qual $77 \%$ dos entrevistados responderam que investiriam num plano de previdência. Confirmando-se também a crença de que haveria o recebimento da aposentadoria (80\%).

Por outro lado, as pessoas não contribuiriam com o INSS, caso este fosse facultativo, conforme demonstra o índice de $67 \%$. Um dos fatores que pôde influenciar essa decisão é que a maioria dos entrevistados acha que não receberia o benefício do INSS quando se aposentassem (63\%).

Porém isso não faz com que as pessoas invistam (73\%) em um plano de previdência complementar à sua aposentaria do INSS, nem faz com que elas troquem o INSS (67\%) pela previdência privada caso possam.

Em relação às denúncias de fraude no INSS, 73\% acham que as mesmas vão interferir em sua aposentadoria futura. Já as denúncias de fraude contra os planos de previdência não revelam ser tão importantes para o entrevistado a ponto de acharem que iriam interferir em suas aposentadorias futuras (73\%).

Portanto, segurança é o diferencial que $39 \%$ dos entrevistados acham que o INSS tem em relação aos planos de previdência. Rentabilidade, por outro lado, é o atributo que os entrevistados acham que o plano de previdência privada tem em relação ao INSS.

Os resultados deste estudo apontam, então, que as pessoas tem mais segurança no INSS, o que faz com que elas não troquem o INSS pelos planos de previdência privada embora achem que talvez não recebam seu benefício futuramente.

Porém, entre os entrevistados, os planos de previdência privada são considerados uma das melhores opções de investimentos para a aposentadoria, pois a rentabilidade é maior que no INSS, o que revela a intenção dos entrevistados de investir neles, principalmente, pelo fato de $70 \%$ dos entrevistados quererem mais de nove salários mínimos quando se aposentarem. 


\section{CONCLUSÕES E RECOMENDAÇÕES}

Neste trabalho, objetivou-se refletir sobre a influência do comportamento humano em relação ao crescimento dos fundos de investimentos, trabalhando com probabilidade subjetiva. De acordo com Thaler (1999), a compreensão do elemento humano pode enriquecer o entendimento do mercado financeiro. As finanças comportamentais defendem, então, que alguns fenômenos financeiros podem ser entendidos através da utilização de modelos nos quais os agentes não são totalmente racionais. Especificamente, estas analisam o que acontece quando se deixa de lado um ou ambos os princípios que suportam a racionalidade individual. (BARBERIS, THALER, 2002). De forma mais ampla, as finanças comportamentais se constituem em um campo de estudo que se dedica a compreender a irracionalidade humana em mercados competitivos (SHLEIFER, 2000).

Nesse sentido, explanou-se sobre os benefícios oferecidos pelo INSS e pelos fundos de pensão e as suas inconsistências em relação a fraudes e perdas propositais de capital. Posteriormente, analisaram-se os dados estatísticos da ABRAPP, IBGE e DATAPREV, que demonstraram o alcance social dos programas do governo federal e a vultosa soma de recursos que os fundos de investimentos possuem.

Em seguida, foi inserido o resultado do questionário aplicado à turma de Ciências Contábeis da Universidade Federal de Santa Catarina, no qual se conseguiu mensurar as expectativas de um determinado grupo em relação a sua aposentadoria. Foi nesse ponto que se verificou algumas inconsistências próprias do comportamento humano, como: embora achem que não receberiam seu benefício futuramente, a maioria das pessoas tem mais segurança no INSS, o que faz com que elas não troquem o mesmo pelos planos de previdência; outro viés seria o resultado que aponta que a maioria dos entrevistados não investiria em previdência privada para complementar sua aposentadoria, embora achem ser essa uma das melhores opções de investimentos, pois sua rentabilidade é maior. Perante os pesquisados, constatou-se que há potencial no crescimento do mercado de fundos de investimento (público e privado), porque as pessoas têm intenção de investir neles, o que retrata a consequente procura por tal alternativa. Porém, de outro lado, o INSS continuará sendo a alternativa de investimento, principalmente pelo fato de aplicar várias políticas sociais e pela segurança que desperta nas pessoas. Isso mostra a tendência de que os fundos de investimentos serão a alternativa mais procurada para complementação de renda. Diante do exposto, percebe-se que agregar, em modelos econômicos, o comportamento humano, faz com que as previsões de crescimento reflitam melhor a realidade do setor estudado. 


\section{REFERÊNCIAS BIBLIOGRAFICAS}

ASSOCIAÇÃO BRASILEIRA DAS ENTIDADES FECHADAS DE PREVIDÊNCIA COMPLEMENTAR - ABRAPP. Consolidado Estatistico. Disponível em: $\quad$ http://www.abrapp.org.br/portal/ conteudo.asp?Areald=197>. Acesso em: 13 jun. 2007.

BANCO DE POUPANÇA E CRÉDITO. Fundo de Pensão. Disponível em: <http://www.bpc.ao/ glossario_f.htm>. Acesso em: 13 jun. 2007.

BARBERIS, Nicholas; THALER, Richard. A survey of behavioral finance. New York: National Bureau of Economic Research, 2002. Working paper n. 9222.

BEGG, David K. H. The Rational Expectations Revolution in Macroeconomics. Oxford: Phillip Allan, 1982

IBGE ( INSTITUTO BRASILEIRO DE GEOGRAFIA E ESTATÍSTICA). Brasil já tem mais de $\mathbf{1 8 0}$ milhões de habitantes. Disponível em: <http:// www.ibge.gov.br/home/presidencia/noticias/ noticia_visualiza.php?id_noticia $=207 \& i d$ pagina=1>. Acesso em: 11 jun. 2007.

OS FUNDOS CITADOS. In: Jornal do Brasil - 22/06/2006. Resenha Eletronica. Disponível em: <http://www.fazenda.gov. $\mathrm{br} /$ resenhaeletronica/MostraMateria. asp?cod=268207>. Acesso em: 12 jun. 2007.

ESCÂNDALO DOS FUNDOS DE PENSÃO (MENSALÃO). In: Jornal do Senado. Disponível em: <www.senado.gov.br/noticias/jornal/ edicoes/2006>. Acesso em 15 jun. 2007.

MARTINEZ, Wladimir Novaes. Direitos dos Idosos. São Paulo: LTR, 1997.

MENEZES, Emilio. Risco. Disponível em: <webensino.ufsc.br>. Acesso em: 13 jul. 2007.

LAVANDERIA DO MENSALÃO. In: Revista Época.

Disponível em: <http://revistaepoca.globo.
com/Revista/Epoca/0,,EDG 71523-6009,00. html>. Acesso em: 12 jun. 2007.

SHLEIFER, Andrei. Inefficient markets: an introduction to behavioral finance. Oxford: Oxford University Press, 2000.

TVERSKY, Amos; KANEMAN Daniel. Judgment under uncertainty: Heuristics and Biases. Science, New Series, Vol. 1985, Issue 4157, 1974. 